Supporting Information for:

\title{
Selective Detection of 8-Oxo-2'-Deoxyguanosine in Single-Stranded DNA via Nanopore Sensing Approach
}

Lei Liu, ${ }^{\mathrm{a}}$ Y uru Li, ${ }^{\mathrm{a}}$ Ting Li, ${ }^{\mathrm{a}}$ Jiani Xie, ${ }^{\mathrm{a}}$ Chaofei Chen, ${ }^{\mathrm{b}}$ Quansheng Liu, ${ }^{\mathrm{b}}$ Shouwen Zhang ${ }^{\mathrm{c}}$ and Hai-Chen $\mathrm{Wu}^{\star \mathrm{a}}$

${ }^{\mathrm{a}}$ Key Laboratory for Biomedical Effects of Nanomaterials \& Nanosafety, Institute of High Energy Physics, Chinese Academy of Sciences, Beijing 100049, China. E-mail:

leiliu@ihep.ac.cn or haichenwu@ihep.ac.cn ; Fax: +86-10-88235745; Tel: +86-10-88235745.

${ }^{\mathrm{b}}$ Multidisciplinary Center, Institute of High Energy Physics, Chinese Academy of Sciences, Beijing 100049, China.

${ }^{c}$ Epilepsy Department, Beijing ChaoYang Emergency Medical Center, Beijing 100021, China. 


\section{Materials and Methods}

Materials and characterization. 1,2-Diphytanoyl-sn-glycero-3-phosphocholine (DPhPc) was purchased from Avanti Polar Lipids (Beijing distributor). All the other DNA oligomers were purchased from Sangon Biotech (Shanghai). All chemicals were purchased from Sigma-Aldrich, Alfa Aesar and J\&K, and used without further purification. Micro Bio-Spin P6 gel columns (Tris buffer) were purchased from Bio-Rad (Hercules, CA). $\alpha \mathrm{HL}$ wildtype-D8H6 was produced by expression in BL21 (DE3) pLysS Escherichia coli cells and self-assembled into heptamers. ${ }^{32}$ All the columns were pre-equilibrated three times with 80 $\mu \mathrm{L}$ deionised water prior to use. All the DNA samples and buffers were prepared in deionised water (Millipore, MA). DNA mass spectrometry was analysed on Thermo-Finnigan LCQ Deca XP Plus. HRMS data of new compounds were obtained using Bruker ultrafleXtreme MALDI-TOF/TOF. NMR spectra were recorded on Bruker Avance III 500 spectrometers. FT-IR measurements were performed on a Bruker Tensor27 spectrometer. DNA concentration was measured on Malcom e-spect ES-2.

Buffer preparation. $22.365 \mathrm{~g}$ of $\mathrm{KCl}(99.999 \%$, Sigma-Aldrich) and $0.121 \mathrm{~g}$ of Tris $\cdot \mathrm{HCl}$ (99.0\%, Sigma-Aldrich) were dissolved in $80 \mathrm{~mL}$ of deionized water (Millipore, MA). $2 \mathrm{M}$ $\mathrm{NaOH}$ was used to adjust the $\mathrm{pH}$ to 8.0. The solution was diluted with deionized water to 100 $\mathrm{mL}$. The final buffer solution consists of $3 \mathrm{M} \mathrm{KCl}$ and $10 \mathrm{mM}$ Tris at $\mathrm{pH}$ 8.0.

\section{OG-DNA modification.}

Reaction with $\mathrm{R}-\mathrm{NH}_{2}$. The modification of OG was conducted according to the method described in literature. ${ }^{9}$ Typically, $10 \mu \mathrm{L}$ OG-containing ssDNA $(100 \mu \mathrm{M})$ was incubated with $37.5 \mu \mathrm{L}$ phosphate buffer (0.2 M, pH 8), $10 \mu \mathrm{L}$ R-NH ${ }_{2}$ aqueous solution $(20 \mathrm{mM})$ and $10 \mu \mathrm{L}$ deionized water at $45{ }^{\circ} \mathrm{C}$ for $30 \mathrm{~min}$, followed by the reaction with $3 \mu \mathrm{L} \mathrm{Na}_{2} \operatorname{IrCl}_{6}(5$ $\mathrm{mM}$ ) at $45{ }^{\circ} \mathrm{C}$ for $1 \mathrm{~h}$. Then, the reaction was quenched by the addition of $5 \mu \mathrm{L}$ EDTA (20 $\mathrm{mM}, \mathrm{pH}$ 8) and the product was purified with Micro Bio-Spin P6 columns. The collected product (Sp-NRs) was lyophilized for the next reactions. $\mathrm{R}_{-} \mathrm{NH}_{2}$ represents 1,12-dodecanediamine, 4-pentyn-1-amine or 3,6,9,12,15-pentaoxaheptadecane-1,17-diamine, etc.

Reaction with $\mathrm{Ad}^{-\mathrm{C}_{3}-\mathrm{NHS}^{27}} 3.33 \mu \mathrm{L}$ Sp-NRs (100 $\mu \mathrm{M}$ in deionized water), $4 \mu \mathrm{L}$ phosphate buffer (0.2 M, pH 9), $4 \mu \mathrm{L}$ Ad-C ${ }_{3}$-NHS (50 mM in DMSO) and $8.67 \mu \mathrm{L}$ deionized 
water were mixed together and incubated at $45^{\circ} \mathrm{C}$ for $4 \mathrm{~h}$. The product (Sp-Ad) was purified with Micro Bio-Spin P6 columns.

Coupling with $\mathrm{N}_{3}-\mathrm{PEG}_{4}-\mathrm{FC}$. The coupled reaction was achieved by $\mathrm{Cu}(\mathrm{I})$-catalyzed click chemistry. $3.33 \mu \mathrm{L}$ Sp-Alkyne $(100 \mu \mathrm{M})$ was mixed with $2 \mu \mathrm{L}$ HEPES buffer $(100 \mathrm{mM}, \mathrm{pH}$ 7.4), $2 \mu \mathrm{L} \mathrm{N}_{3}-\mathrm{PEG}_{4}-\mathrm{Fc}(100 \mathrm{mM}$ in DMSO$), 1 \mu \mathrm{L}$ sodium ascorbate $(20 \mathrm{mM}), 0.5 \mu \mathrm{L}$ copper(II) nitrate $(20 \mathrm{mM})$ and $1.17 \mu \mathrm{L}$ deionized water (total volume: $10 \mu \mathrm{L}$ ). Then, the mixture was incubated at $25^{\circ} \mathrm{C}$ for $2 \mathrm{~h}$. The reaction was quenched by EDTA $(5 \mu \mathrm{L}, 20 \mathrm{mM}$, $\mathrm{pH}$ 8) and the sample was purified with Micro Bio-Spin P6 columns to afford the Fc-modified Sp-Fc.

Host-Guest interactions between FC, Ad and CB[7]. Sp-Ad or Sp-Fc (5 $\mu \mathrm{M}, 20 \mu \mathrm{L})$ was incubated with $10 \mu \mathrm{L} \mathrm{CB}$ [7] ( $5 \mathrm{mM})$ at room temperature for $2 \mathrm{~h}$ to afford the product.

\section{Syntheses and characterization of new compounds.}<smiles>O=C(CCCNC(=O)C12CC3CC(CC(C3)C1)C2)ON1C(=O)CCC1=O</smiles>

\section{Ad- $\mathrm{C}_{3}-\mathrm{NHS}$}

The Ad- $\mathrm{C}_{3}$-NHS was prepared according to literature. ${ }^{\mathrm{S} 1}$ All the known compounds were characterized with ${ }^{1} \mathrm{H}$ NMR and MS and their spectroscopic data were identical to that reported in the literature.
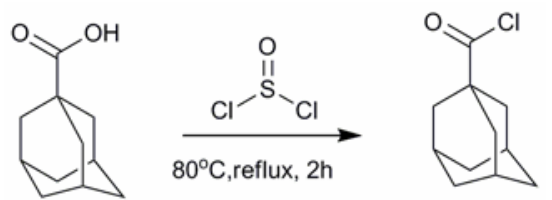

Synthesis of adamantane-1-chloride. $2 \mathrm{~mL}$ anhydrous thionyl chloride was added into 1-adamantane carboxylic acid $(1.0 \mathrm{~g}, 5.55 \mathrm{mmol})$ under the protection of nitrogen atmosphere at room temperature. Then, the mixture was heated up to $80^{\circ} \mathrm{C}$ and refluxed for $2 \mathrm{~h}$ before cooling down to room temperature. The residual thionyl chloride was removed by vacuum 
extraction to afford the product adamantane-1-chloride (yellow solid, $1.1 \mathrm{~g}$, and yield: 99\%).

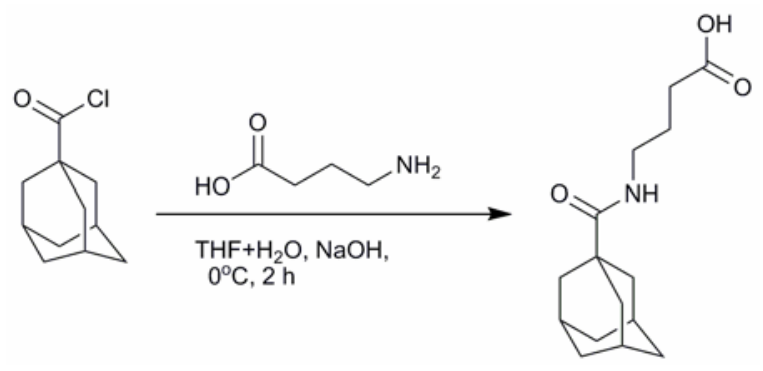

Synthesis of $\mathrm{Ad}-\mathrm{C}_{3}-\mathrm{COOH}$. Adamantane-1-carbonyl chloride (1.1g, $\left.5.54 \mathrm{mmol}\right)$ was dissolved in $3.33 \mathrm{~mL}$ anhydrous tetrahydrofuran which was cooled in an ice bath. Then, the solution was added dropwise into $10 \mathrm{~mL} \mathrm{NaOH}(1.27 \mathrm{M})$ which contained 4-amino butyric acid $(0.858 \mathrm{~g}, 5.33 \mathrm{mmol})$, followed by a $2 \mathrm{~h}$ stirring in an ice bath. Next, hydrochloric acid was slowly added into the mixture until the solution $\mathrm{pH}$ dropped to 3 . The mixture was extracted by $30 \mathrm{~mL}$ diethyl ether, dried with anhydrous $\mathrm{MgSO}_{4}$, and evaporated under reduced pressure to afford the product $\mathrm{Ad}_{-} \mathrm{C}_{3}-\mathrm{COOH}$ (0.98 g; yield: 66.7\%).

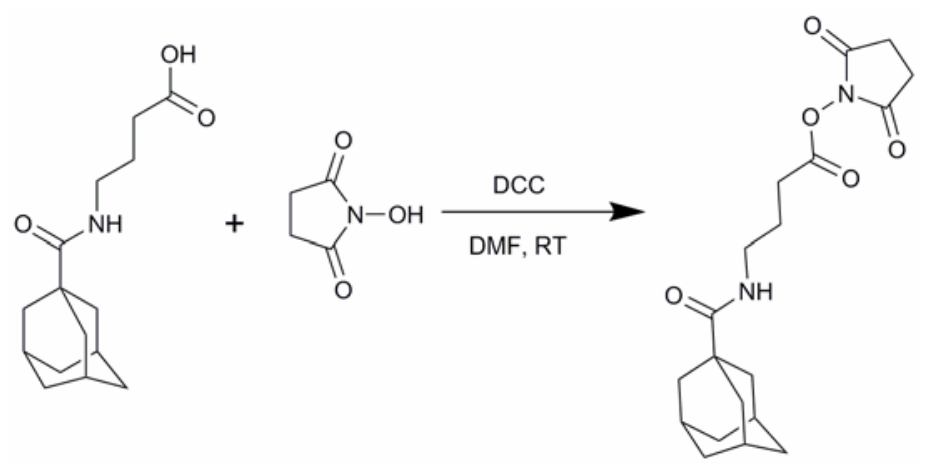

Syntheses of $\mathrm{Ad}_{-} \mathrm{C}_{3}-\mathrm{NHS}$. Under the protection of nitrogen atmosphere, $\mathrm{Ad}-\mathrm{C}_{3}-\mathrm{COOH}$ (400 mg, $1.51 \mathrm{mmol}), N$-hydroxysuccinimide $(174 \mathrm{mg}, 1.51 \mathrm{mmol})$ and $5 \mathrm{~mL}$ anhydrous DMF were mixed together. To the mixture was added $2 \mathrm{~mL}$ DCC solution $(621 \mathrm{mg}, 3.01$ mmol) which was stirred at room temperature for $12 \mathrm{~h}$. Then, the solution was filtered to remove the side product DCU, and purified on a silica gel column (eluant: dichloromethane/ methanol $=200 / 1)$. The obtained product was white solid $(350 \mathrm{mg}$; yield $64 \%)$. ${ }^{1} \mathrm{H}$ NMR (500 MHz, DMSO) $\delta 7.46(\mathrm{t}, J=5.4 \mathrm{~Hz}, 1 \mathrm{H}), 3.10(\mathrm{dd}, J=12.6,6.6 \mathrm{~Hz}, 2 \mathrm{H}), 2.81(\mathrm{~s}, 4 \mathrm{H})$, $2.64(\mathrm{t}, J=7.6 \mathrm{~Hz}, 2 \mathrm{H}), 1.96$ (s, 3H), 1.80-1.54 (m, 14H). ${ }^{13} \mathrm{C}$ NMR (126 MHz, DMSO) $\delta$ 177.53 (s), 170.67 (s), 169.31 (s), 39.18 (s), 38.08 (s), 36.62 (s), 28.31 (s), 28.14 (s), 25.91 (s), 24.82 (s). FT-IR: 3313, 2910, 1743, 1627, 1199, $1072 \mathrm{~cm}^{-1}$. HRMS Exact mass calcd. for $\mathrm{C}_{19} \mathrm{H}_{27} \mathrm{~N}_{2} \mathrm{O}_{5}[\mathrm{M}+\mathrm{H}]: 363.1920$; found 363.1912. 


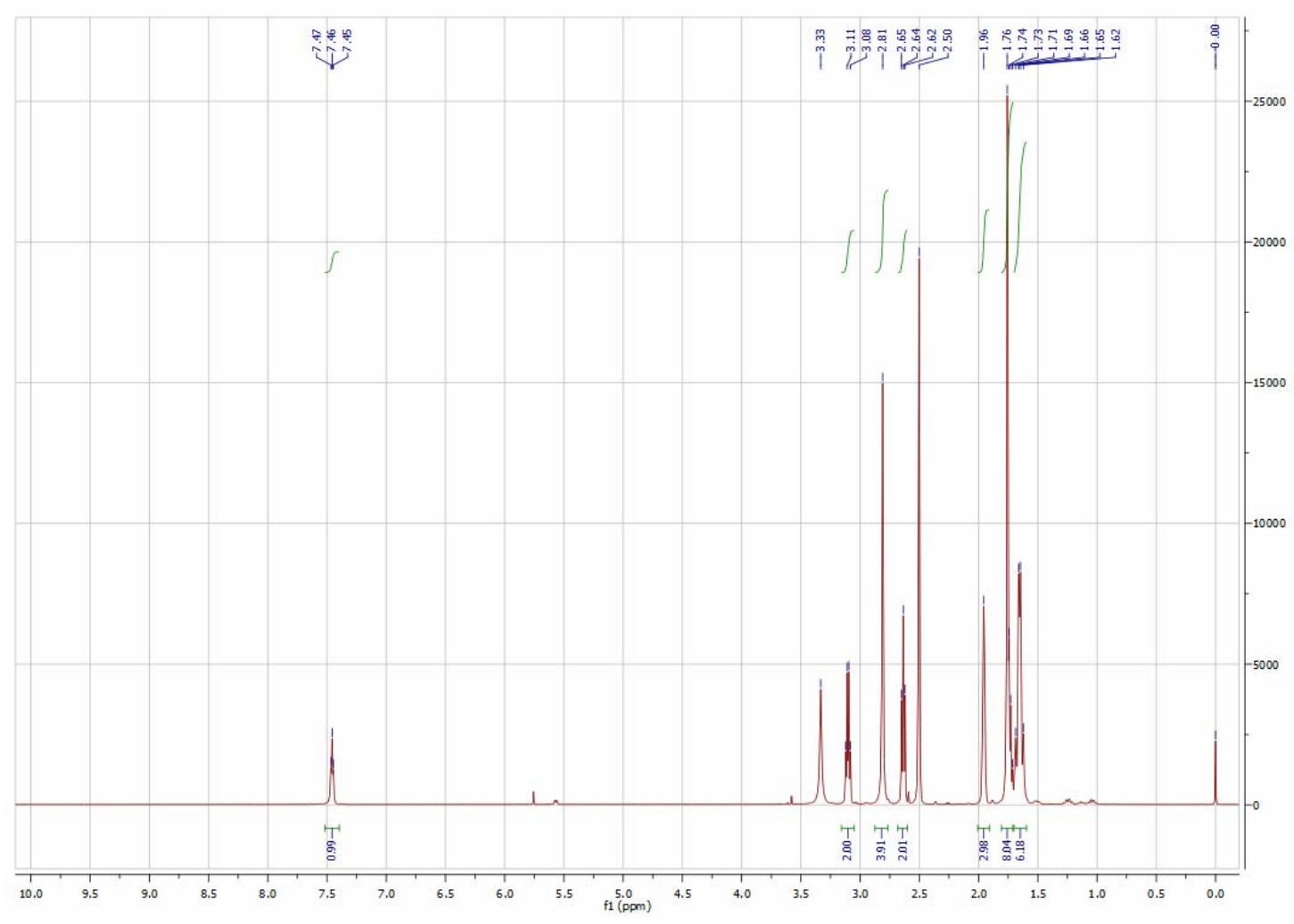

${ }^{1} \mathrm{H}$ NMR spectrum of Ad-C ${ }_{3}$-NHS in DMSO-d6

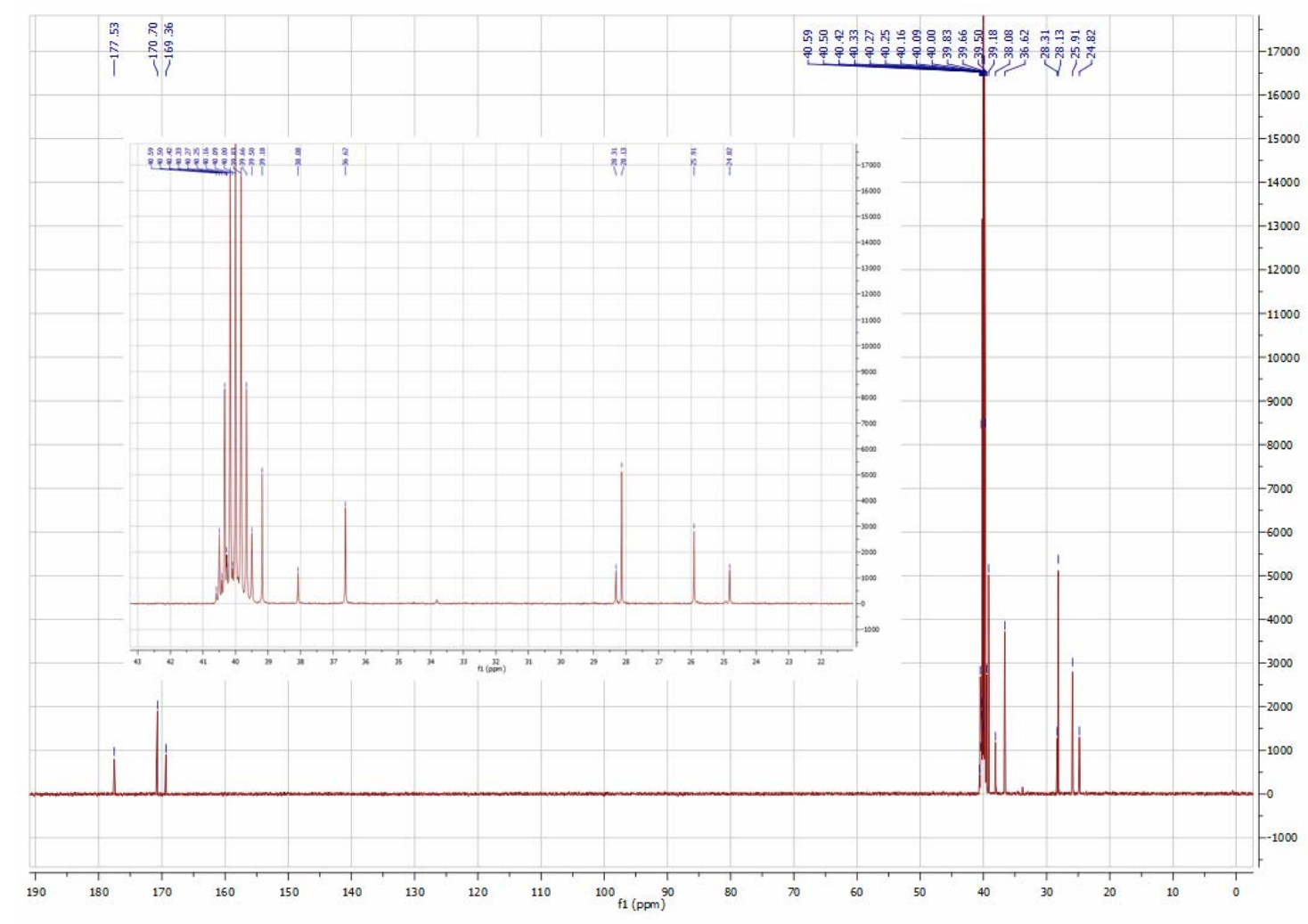

${ }^{13} \mathrm{C}$ NMR spectrum of Ad- $\mathrm{C}_{3}$-NHS in DMSO-d6 


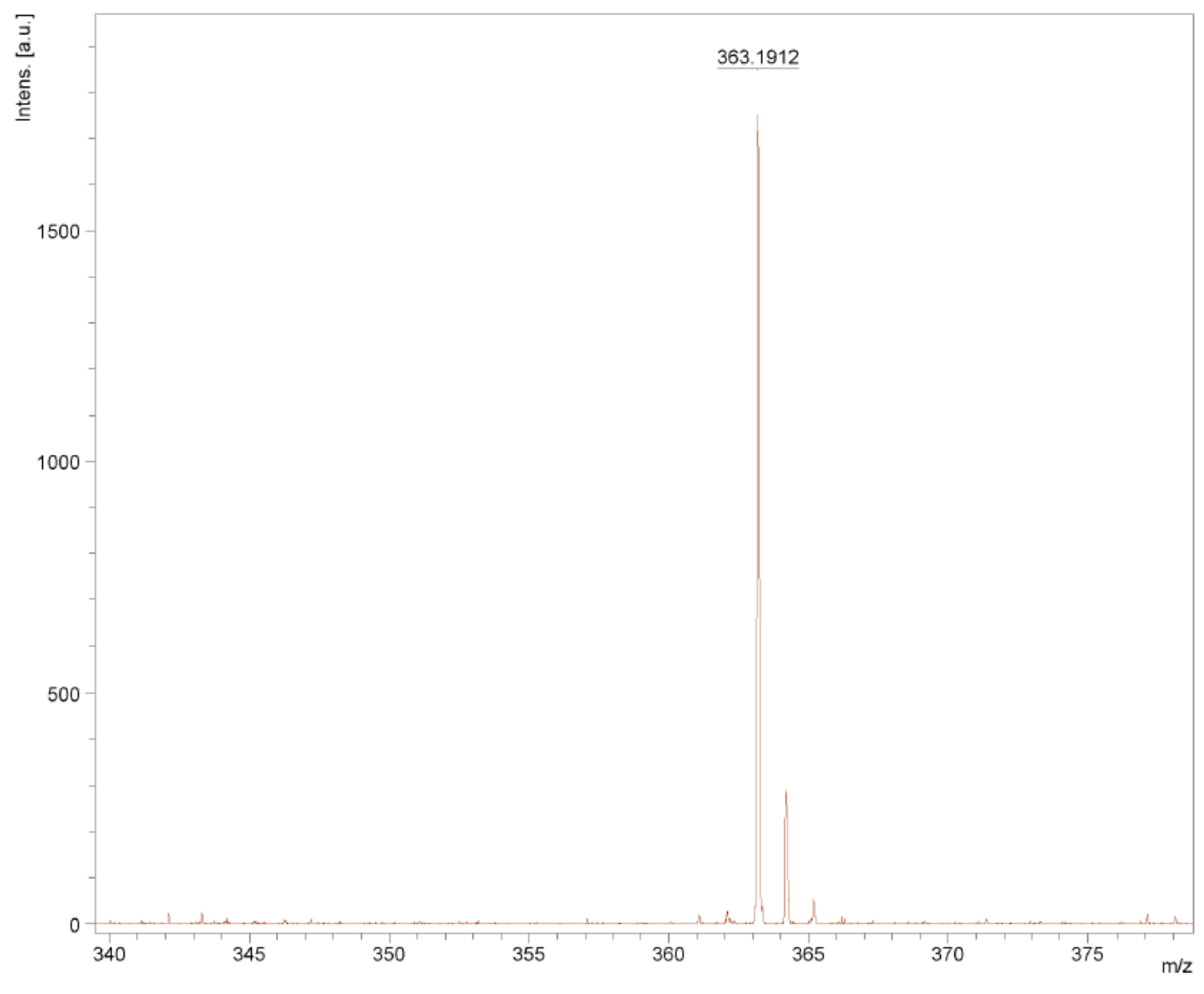

Acquisition Parameter

Date of acquisition

2015-02-04T16:40:15.386+08:00

Acquisition method name

D:IMethodsiflexControlMethodslgc-RP_100-1500_Da.par

Aquisition operation mode

Voltage polarity

Reflector

POS

Number of shots

1000

Name of spectrum used for calibration

Calibration reference list used

sample

HRMS spectrum of Ad- $\mathrm{C}_{3}$-NHS

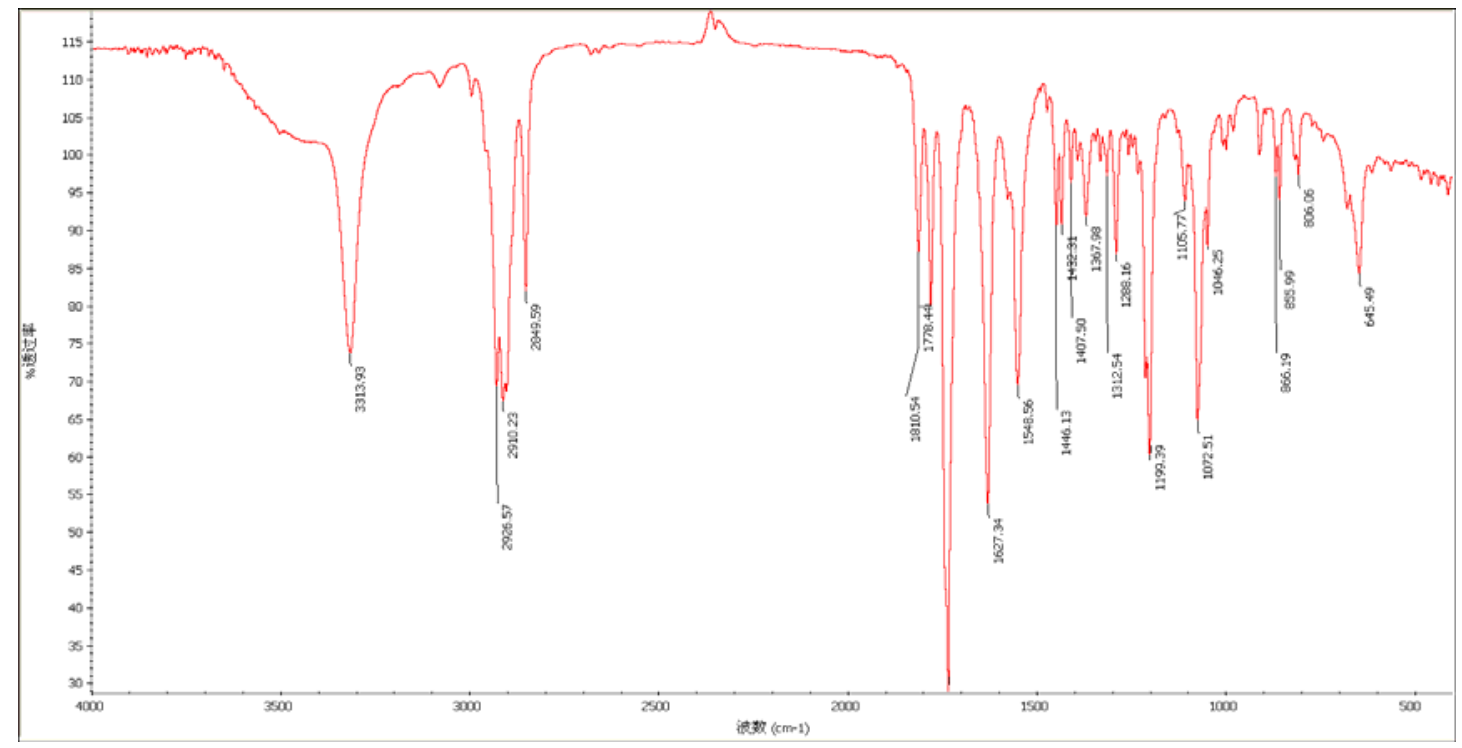

FT-IR spectrum of $\mathrm{Ad}^{-\mathrm{C}_{3}}$-NHS 
Single-channel current recording. A bilayer of $\mathrm{DPhPc}$ was formed across an aperture $100-150 \mu \mathrm{m}$ in diameter in a $20-\mu \mathrm{m}$ thick polytetrafluoroethylene film (Goodfellow, Malvern, PA) that divided a planar bilayer chamber into two compartments, cis and trans. Both compartments contained $1 \mathrm{~mL}$ of buffer. DNA samples were added to the cis compartment, which was connected to ground. The trans compartment was connected to the head-stage of the amplifier. All experiments were carried out in $3 \mathrm{M} \mathrm{KCl}, 10 \mathrm{mM}$ Tris, $\mathrm{pH} 8.0$, at $22.5 \pm 2{ }^{\circ} \mathrm{C}$, unless otherwise stated. Currents were recorded by a patch clamp amplifier (Axopatch 200B; Axon instruments, Foster City, CA) with an internal low-pass Bessel filter operating at $10 \mathrm{kHz}$, and sampled at $100 \mathrm{kHz}$ by a computer equipped with a Digidata $1440 \mathrm{~A} / \mathrm{D}$ converter (Axon instruments).

Data analysis. Current traces were analysed with Clampfit 10.2 software (Axon Instruments). Events were detected using the Event Detection feature, and used to construct amplitude and dwell time histograms. Origin 8.5 (Microcal, Northampton, MA) and Clampfit 10.2 were used for histogram construction, curve fitting and graph presentation. Adobe Illustrator CS2 was used for making figures. 


\section{Supplementary figures}

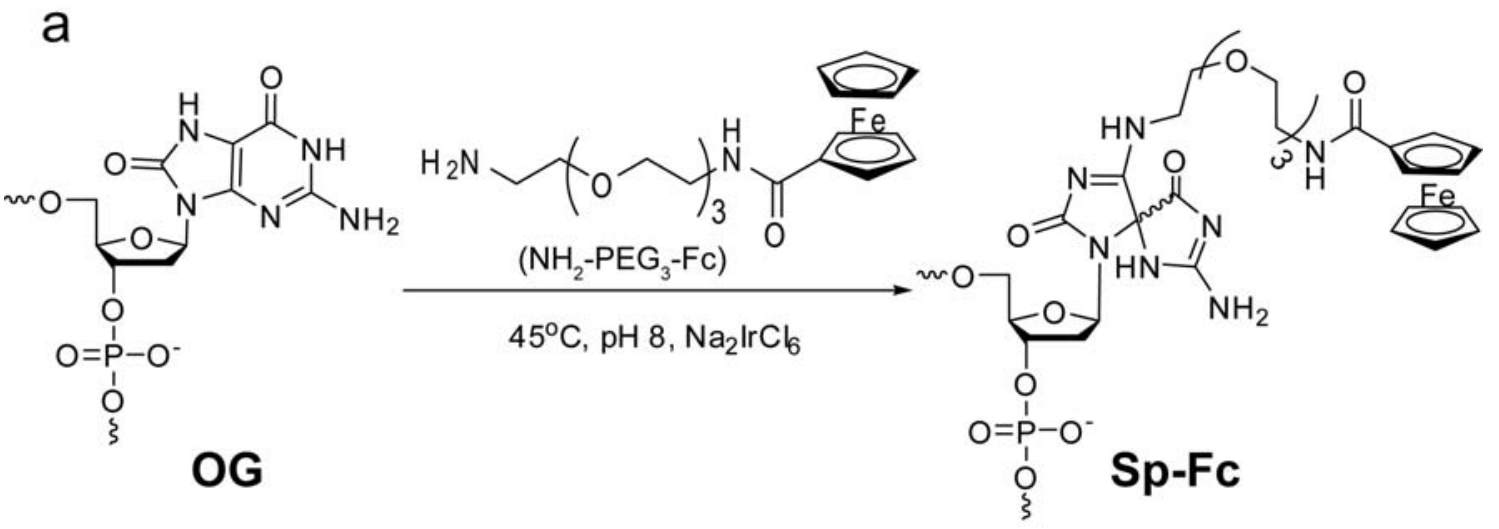

b

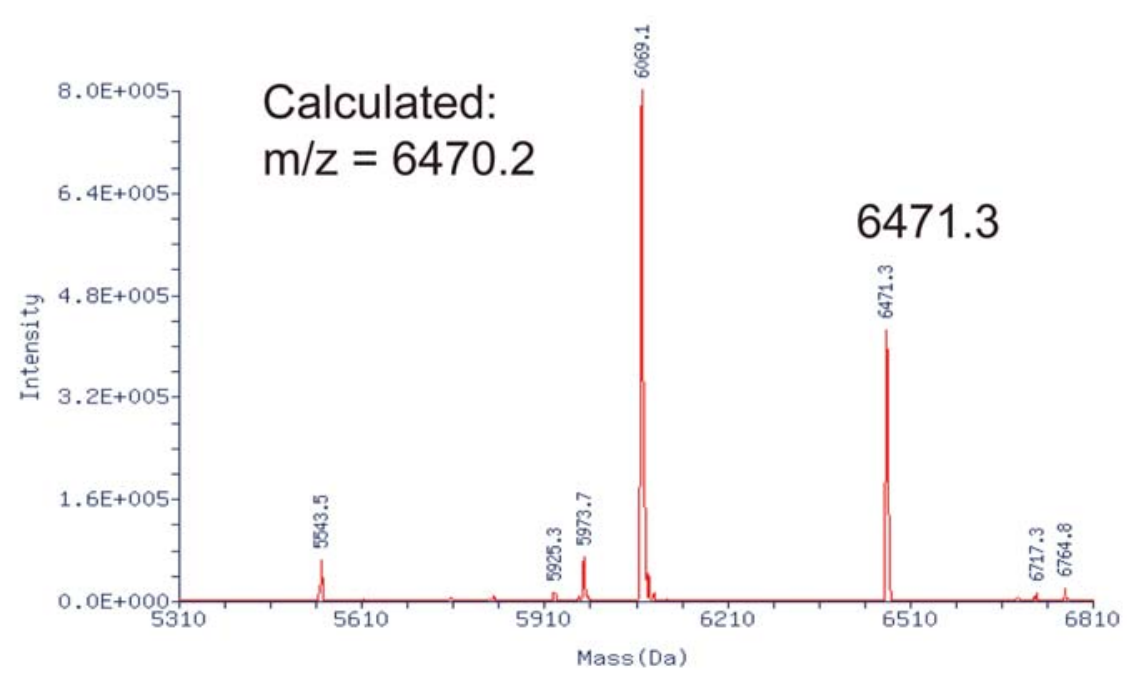

Figure S1. Modification of $\mathrm{OG}$ with $\mathrm{NH}_{2}-\mathrm{PEG}_{3}-\mathrm{Fc}$ and mass spectroscopic characterization.

(a) Chemical reactions of the modification of $\mathrm{OG}$ with $\mathrm{NH}_{2}-\mathrm{PEG}_{3}-\mathrm{Fc}$. (b) Mass spectroscopic characterization of $\mathrm{Sp}-\mathrm{Fc}$. The reaction yield was consistently lower than $40 \%$ even under optimized conditions. 
a
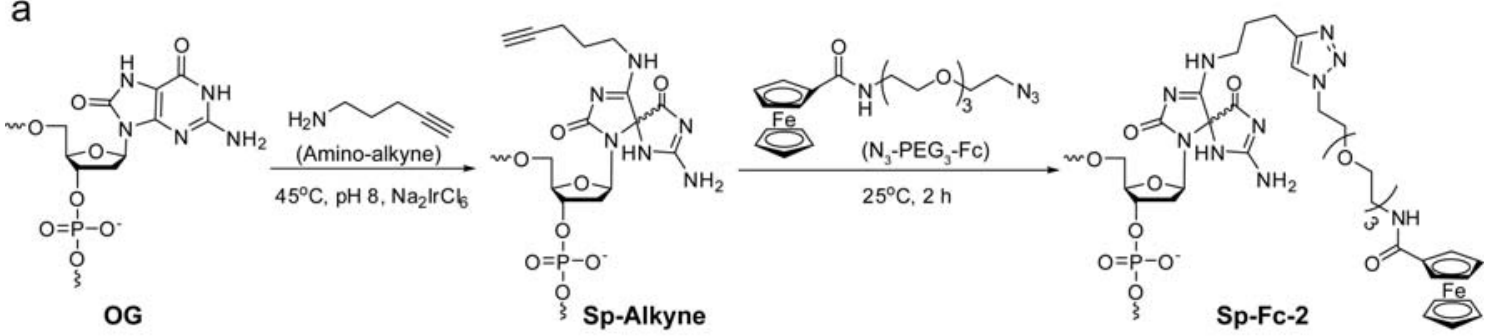

b
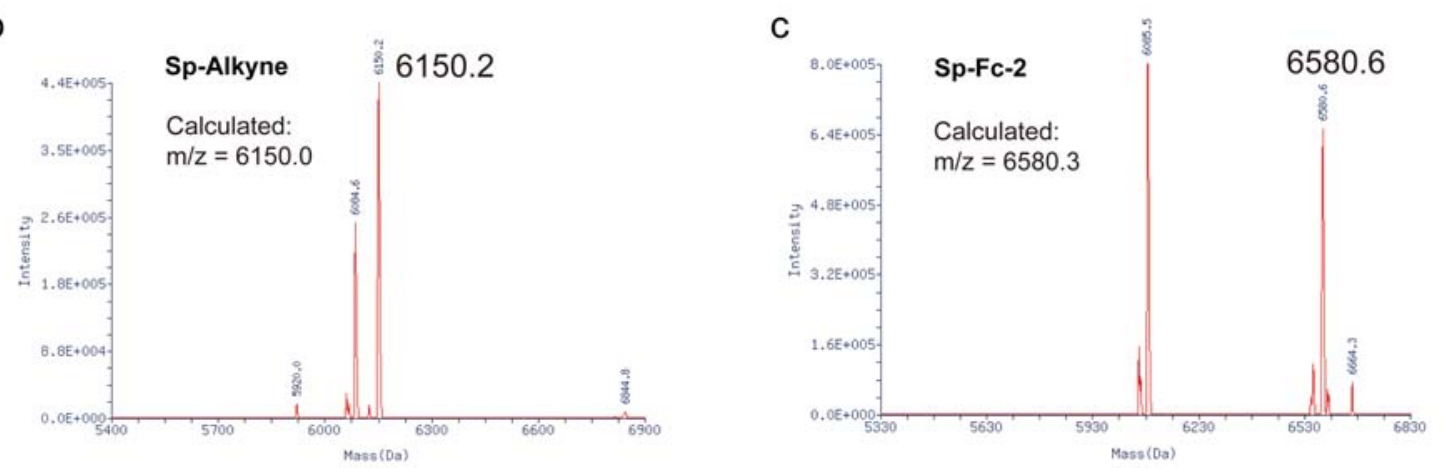

Figure S2. Modification of OG with amino-alkyne and $\mathrm{N}_{3}-\mathrm{PEG}_{3}-\mathrm{Fc}$ in two steps and mass spectroscopic characterization. (a) Reaction of OG with amino-alkyne followed by a "click" reaction with $\mathrm{N}_{3}-\mathrm{PEG}_{3}-\mathrm{Fc}$. (b) Mass spectroscopic characterization of the intermediate product Sp-Alkyne. (c) Mass spectroscopic characterization of the final product Sp-Fc-2. The yield of the first step was about $65 \%$, but the yield of the second step was no higher than $50 \%$. 

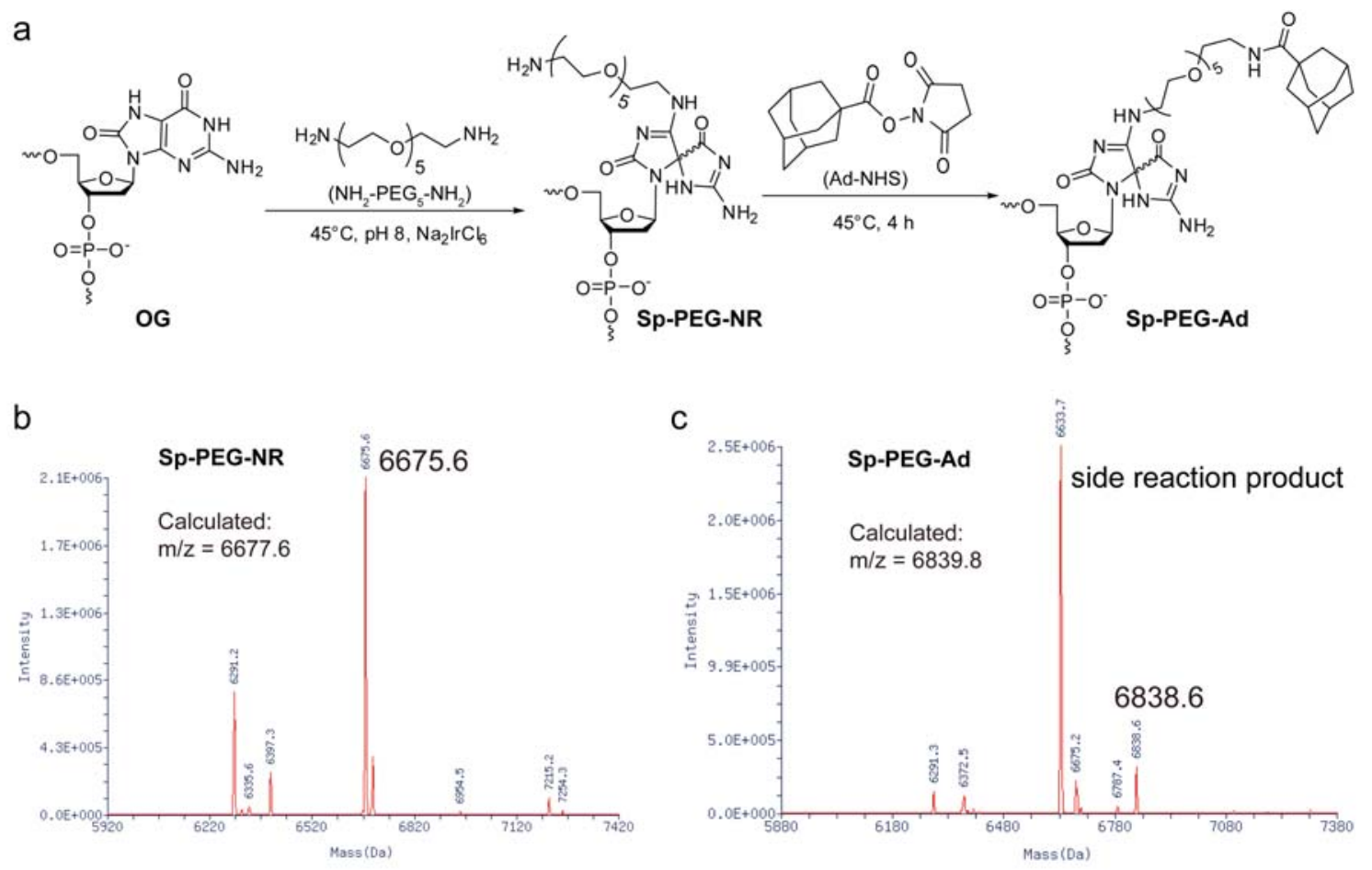

Figure S3. Modification of $\mathrm{OG}$ with $\mathrm{NH}_{2}-\mathrm{PEG}_{5}-\mathrm{NH}_{2}$ and $\mathrm{Ad}-\mathrm{NHS}$ in two steps and mass spectroscopic characterization. (a) Reaction of $\mathrm{OG}$ with $\mathrm{NH}_{2}-\mathrm{PEG}_{5}-\mathrm{NH}_{2}$ followed by a reaction with Ad-NHS. (b) Mass spectroscopic characterization of the intermediate product Sp-PEG-NR. (c) Mass spectroscopic characterization of the final product Sp-PEG-Ad. The yield of the amine coupling step could be as high as $75 \%$ but the second step barely afforded the desired product. 
a
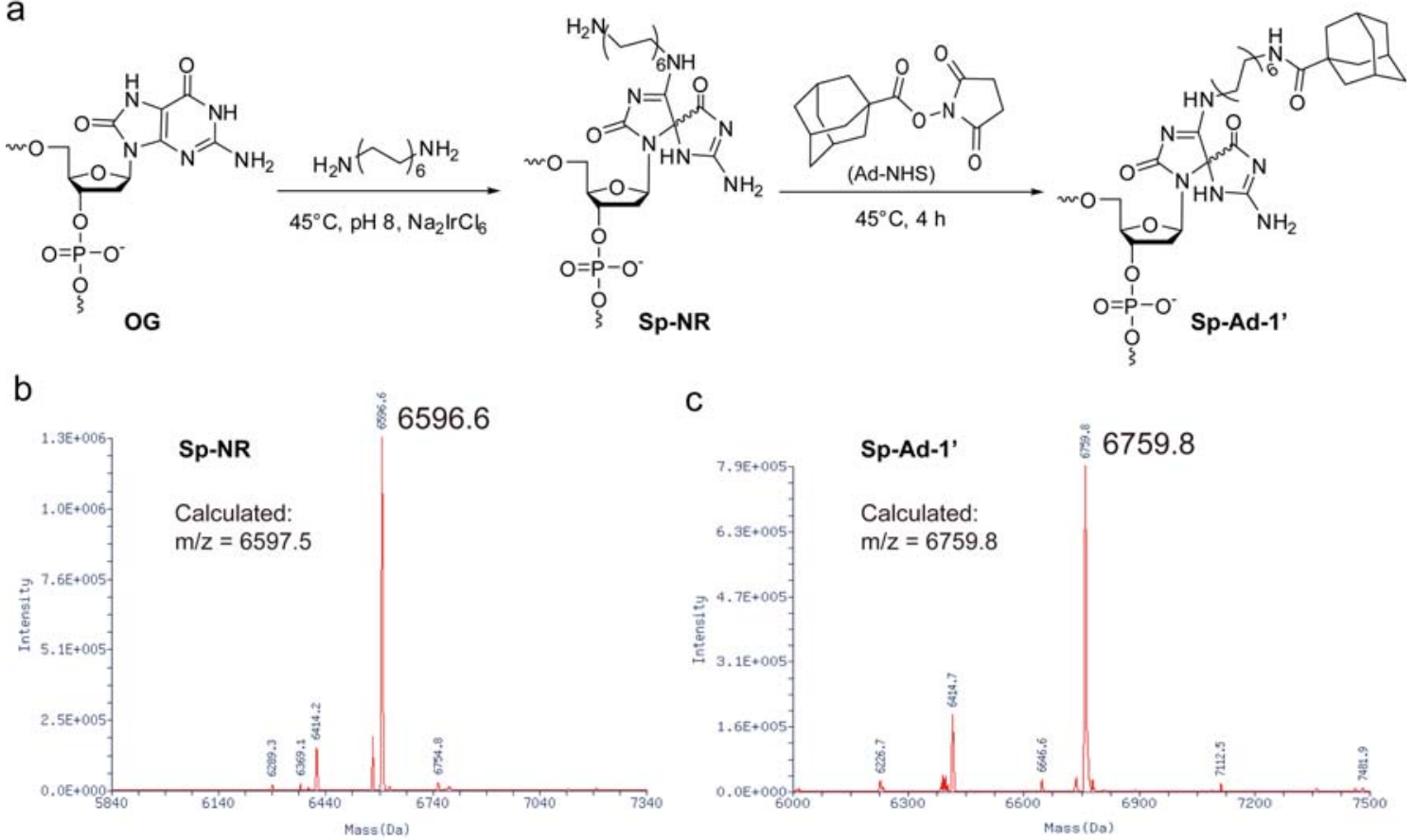

Figure S4. Modification of OG with 1,12-dodecanediamine and Ad-NHS in two steps and mass spectroscopic characterization. (a) Reaction of OG with 1,12-dodecanediamine followed by a reaction with Ad-NHS. (b) Mass spectroscopic characterization of the intermediate product Sp-NR. (c) Mass spectroscopic characterization of the final product Sp-Ad-1'. 
a

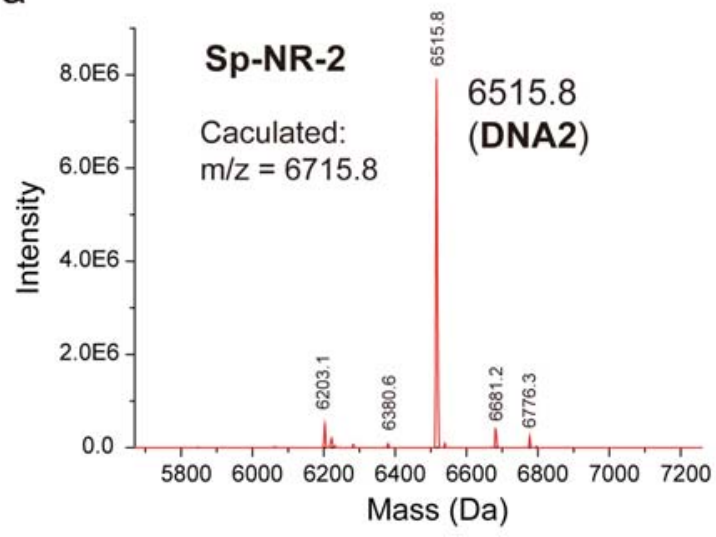

C

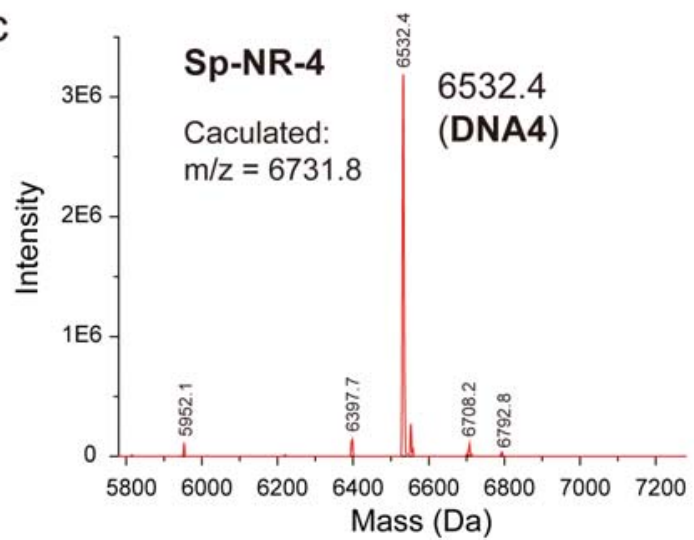

b
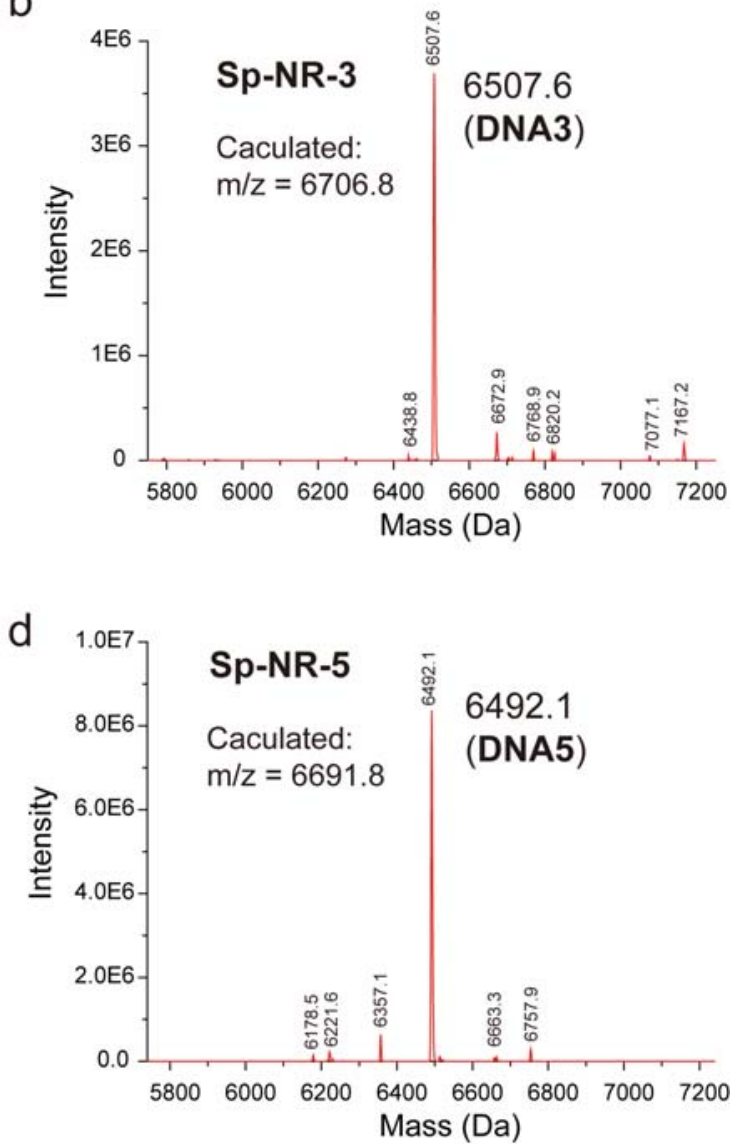

Figure S5. Mass spectroscopic characterization of the products of control DNA2-5 with 1,12-dodecanediamine. (a) Mass spectrometry of the recovered DNA product which is the starting material DNA2. (b) Mass spectrometry of the product (DNA3). (c) Mass spectrometry of the product (DNA4). (d) Mass spectrometry of the product (DNA5). 


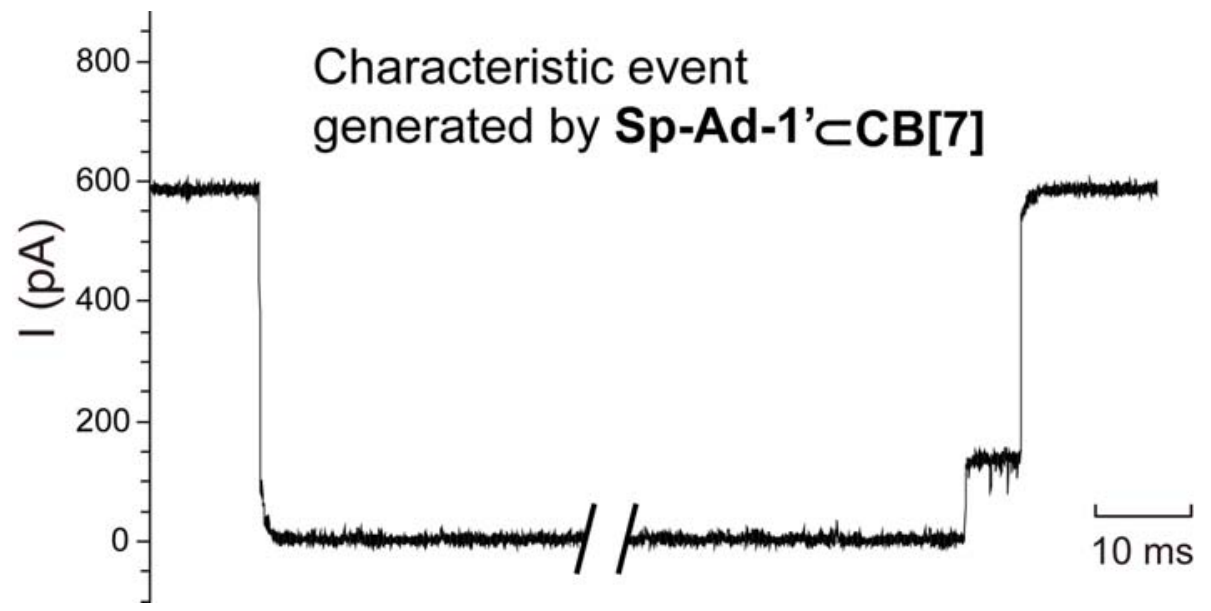

Figure S6. Characteristic event generated during the translocation of Sp-Ad-1' through $\alpha \mathrm{HL}$.

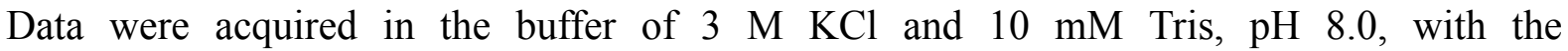
transmembrane potential held at $+200 \mathrm{mV}$. The final concentration of Sp-Ad-1' $\subset \mathrm{CB}$ [7] is $0.25 \mu \mathrm{M}$. 
a
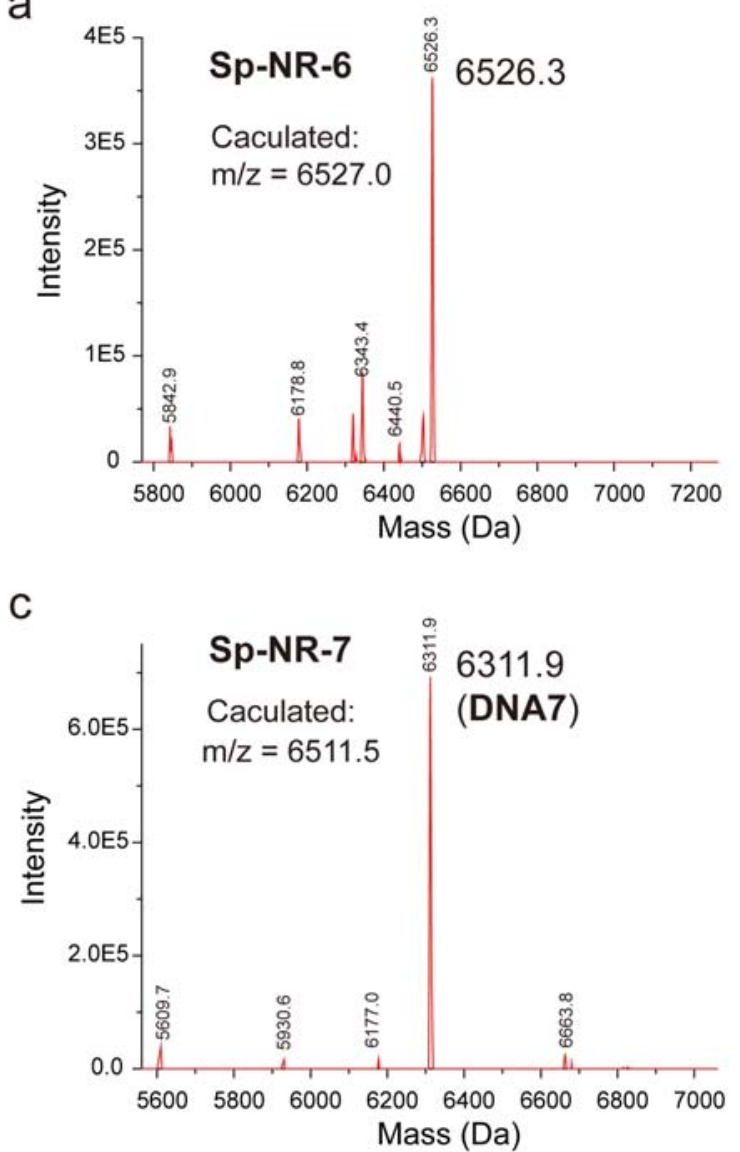

$b$

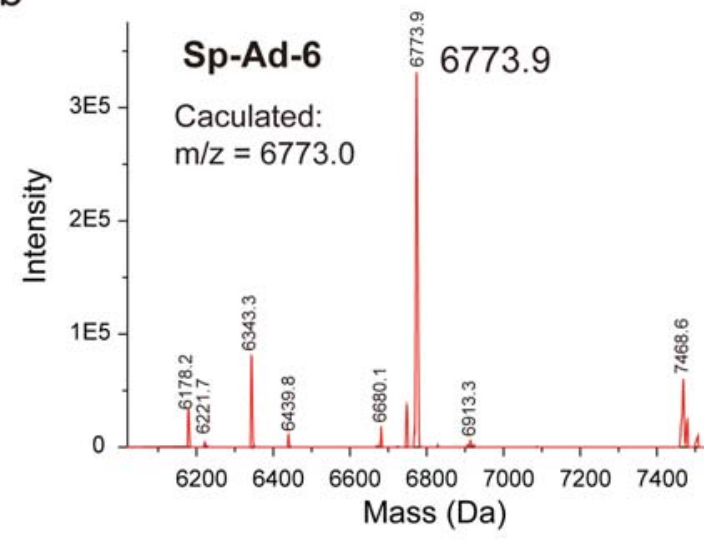

Figure S7. Mass spectroscopic characterization of the products of DNA6 and DNA7 with 1,12-dodecanediamine and Ad- $\mathrm{C}_{3}$-NHS in two steps. (a) Mass spectroscopic characterization of the intermediate product Sp-NR-6. (b) Mass spectroscopic characterization of the final product Sp-Ad-6. (c) Mass spectroscopic characterization of the product of DNA7 with 1,12-dodecanediamine (DNA7). 
a

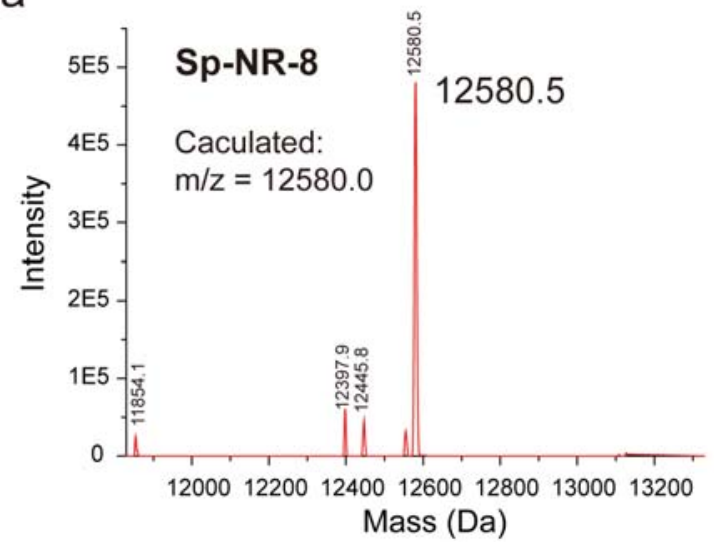

b

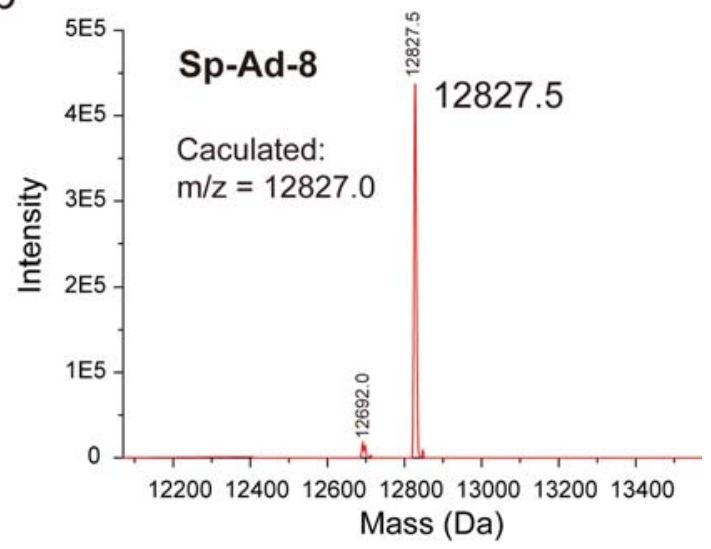

Figure S8. Mass spectroscopic characterization of the products of DNA8 with 1,12-dodecanediamine and Ad- $\mathrm{C}_{3}$-NHS. (a) Mass spectroscopic characterization of the intermediate product Sp-NR-8. (b) Mass spectroscopic characterization of the final product Sp-Ad-8. 

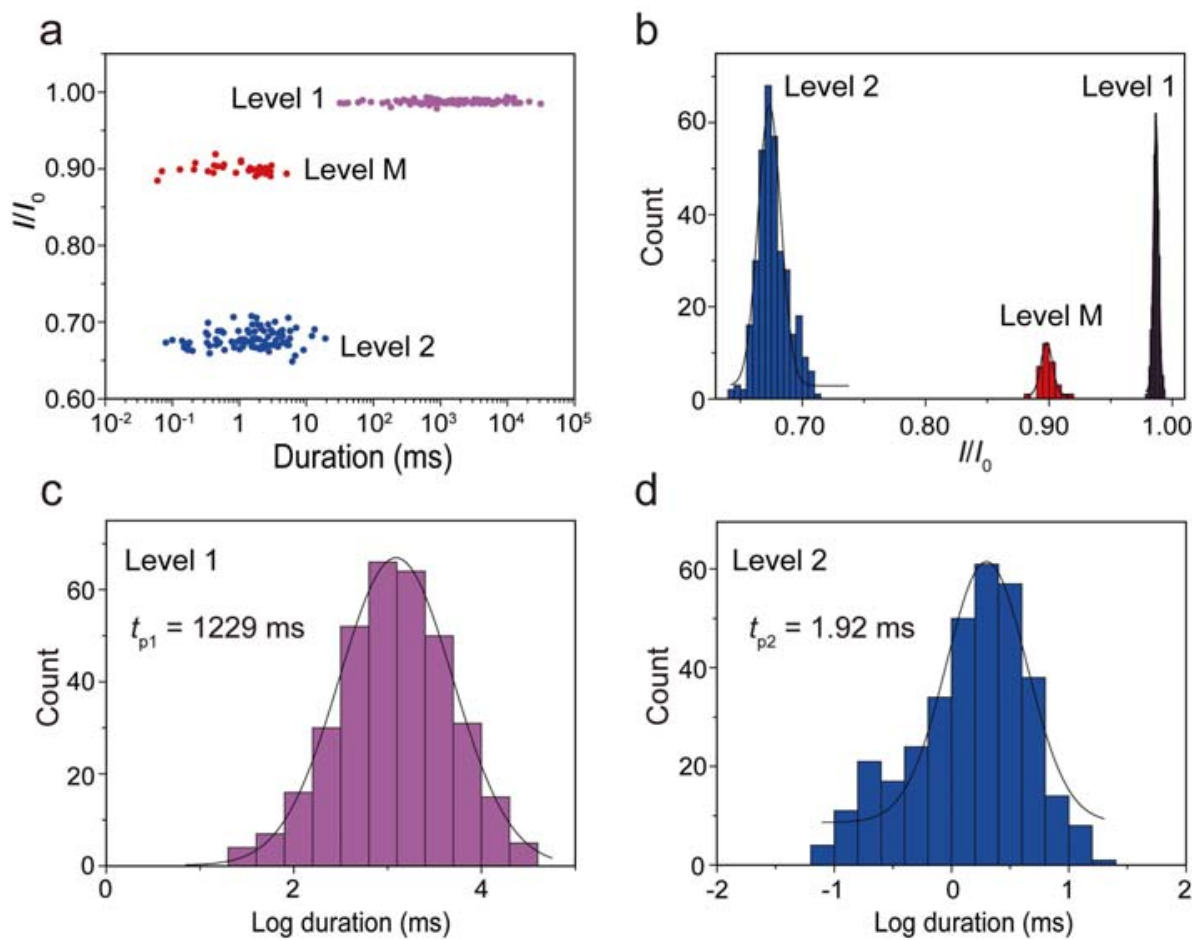

Figure S9. Statistical analysis of the signature events generated by the translocation of

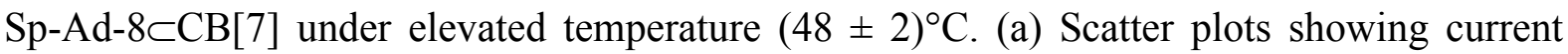
blockades versus event durations of levels 1-2 in the signature events. (b) Histogram of the current blockade of level 1-2. $I_{0}$ stands for open pore current; $I_{1-2}$ stands for the most probable current blockade of level 1-2. The solid lines are Gaussian fit to the histograms. (c,d) Dwell-time histogram of level 1-2. $t_{\mathrm{p} 1-2}$ stands for the most probable duration of level 1-2. The solid lines are Gaussian fit to the histograms. The number of events is 300 . The data were recorded in the buffer of $3 \mathrm{M} \mathrm{KCl}$ and $10 \mathrm{mM}$ Tris, $\mathrm{pH} 8.0$, at $(48 \pm 2)^{\circ} \mathrm{C}$ with the

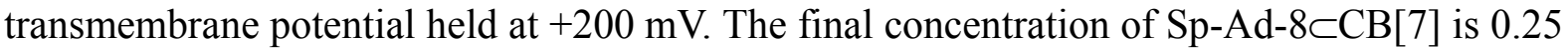
$\mu \mathrm{M}$. 

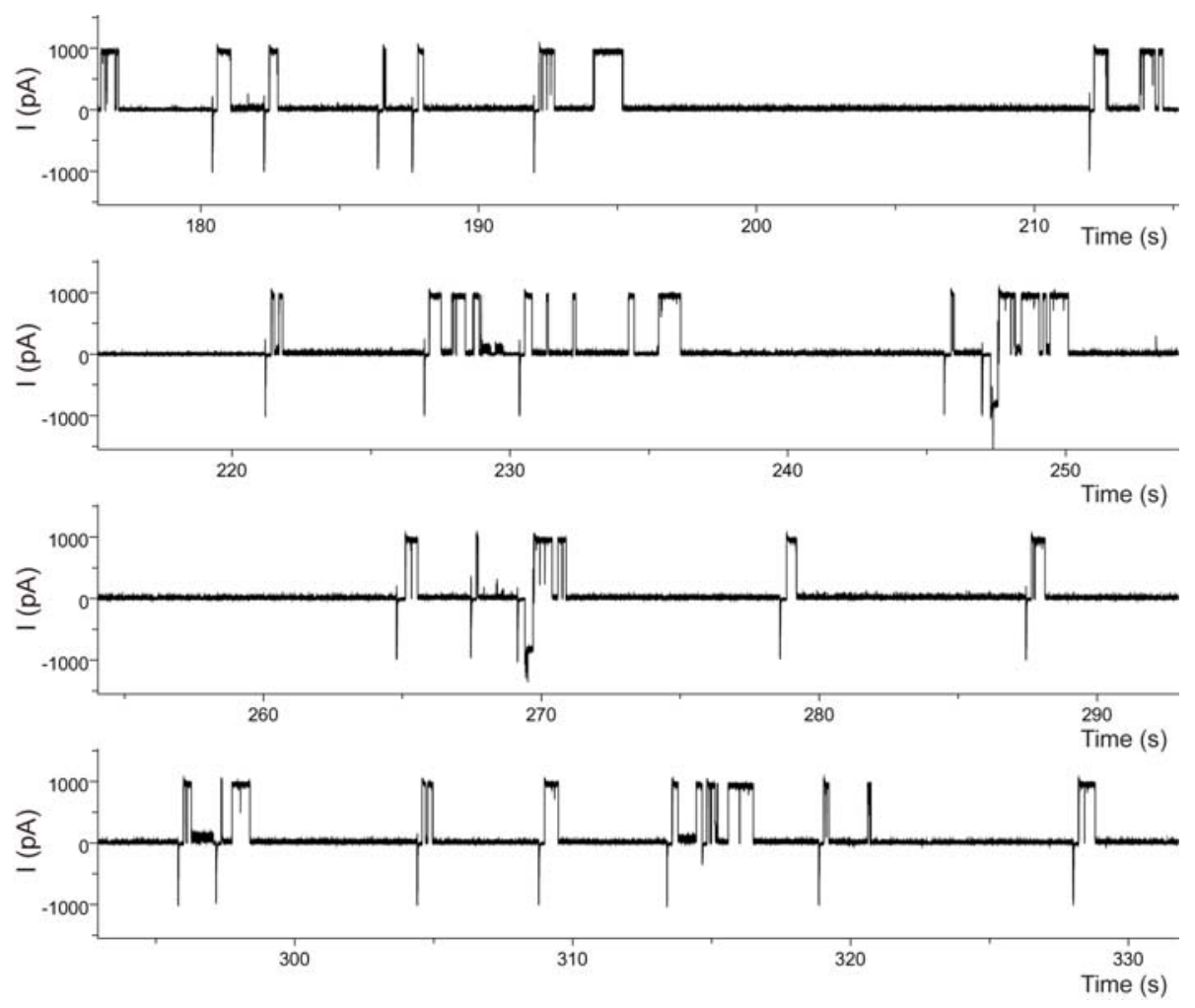

Figure S10. A representative current trace of the translocation of Sp-Ad-9 $\subset \mathrm{CB}$ [7] (final concentration $0.25 \mu \mathrm{M}$ ) through $\alpha \mathrm{HL}$. Data were acquired in the buffer of $3 \mathrm{M} \mathrm{KCl}$ and 10 $\mathrm{mM}$ Tris, $\mathrm{pH} 8.0$, with the transmembrane potential held at $+200 \mathrm{mV}$. The temperature for recording is $(48 \pm 2)^{\circ} \mathrm{C}$. Translocation of the doubly modified Sp-Ad-9 $\subset \mathrm{CB}[7]$ produced very long deep blockage rather than characteristic current signatures. The downward spikes are the points of potential reversal. 


\section{Supplementary tables}

Table S1 Sequences of studied DNA oligomers

\begin{tabular}{|c|c|}
\hline Name & Sequence \\
\hline DNA1 & 5'-AAAAAAAAAA $(\underline{8-0 \times 0 G})$ AAAAAAAAAA-3' \\
\hline DNA2 & 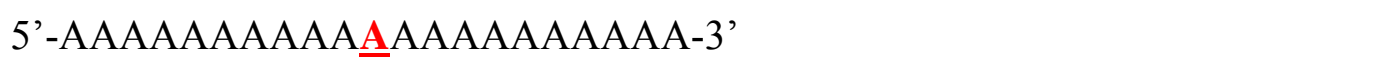 \\
\hline DNA3 & 5'-AAAAAAAAAATAAAAAAAAAA-3' \\
\hline DNA4 & 5'-AAAAAAAAAAGAAAAAAAAAA-3' \\
\hline DNA5 & 5'-AAAAAAAAAAㅌAAAAAAAAAA-3' \\
\hline DNA6 & 5'-CATCGTACAC( $\underline{\text { 8-oxoG }})$ CGCACTACTC-3' \\
\hline DNA7 & 5'-CATCGTACACG GCGCACTACTC-3' \\
\hline DNA8 & 5'-CATCGTCCACCATTGCACAC( $\underline{\mathbf{8 - 0 \times 0 G}})$ CGCACTACTCCATCGAACAC-3' \\
\hline DNA9 & 5'-CCCCCCCCCC $(\underline{8-0 \times 0 G}) \operatorname{CCCCCCCCCC}(\underline{8-0 \times 0 G}) \operatorname{CCCCCCCCCC}-3$ ' \\
\hline \multirow[t]{2}{*}{ DNA10 } & 5'-CCCCCCCCCC $(\underline{8-0 \times 0 G}) \operatorname{CCCCCCCCCCCCCCCCCCCC}(\underline{8-0 \times 0 G})$ \\
\hline & CCCCCCCCCC-3, \\
\hline
\end{tabular}

(8-oxoG $)$-8-oxo-2'-deoxyguanosine 
Table S2 Statistical data of the most probable translocation time $t_{\mathrm{p}}$ and current blockades $\Delta I / I_{0}$ of levels 1-2 during the translocation of modified OG-DNAs through $\alpha H L$.

\begin{tabular}{ccccccc}
\hline & \multicolumn{2}{c}{ Level 1 } & \multicolumn{2}{c}{ Level M } & \multicolumn{2}{c}{ Level 2 } \\
& $t_{\mathrm{p} 1}(\mathrm{~ms})$ & $\Delta I / I_{0}(\%)$ & $t_{\mathrm{pM}}(\mathrm{ms})$ & $\Delta I / I_{0}(\%)$ & $t_{\mathrm{p} 2}(\mathrm{~ms})$ & $\Delta I / I_{0}(\%)$ \\
DNA1 & 483.5 & $99.4 \pm 0.1$ & 7.9 & $92.0 \pm 0.1$ & 18.9 & $67.4 \pm 0.1$ \\
$\begin{array}{c}(25 \pm 1){ }^{\circ} \mathrm{C} \\
\text { DNA1 }\end{array}$ & 33.5 & $98.6 \pm 0.1$ & n.d. & $90.1 \pm 0.1$ & 2.5 & $66.9 \pm 0.1$ \\
$\begin{array}{c}(48 \pm 2){ }^{\circ} \mathrm{C} \\
\text { DNA8 }\end{array}$ & 1229 & $98.7 \pm 0.1$ & n.d. & $89.8 \pm 0.1$ & 2.0 & $67.4 \pm 0.1$ \\
$(48 \pm 2){ }^{\circ} \mathrm{C}$ & & & & & & \\
\hline
\end{tabular}




\section{Supplementary reference}

S1. M. Xu, S. Wu, F. Zeng and C. Yu, Langmuir, 2010, 26, 4529-4534. 